\title{
Maestro de maestros: Miguel León-Portilla (1926-2019)
}

\section{Liliana Weinberg}

Universidad Nacional Autónoma de México, Centro de Investigaciones sobre América Latina y el Caribe, México

\author{
Yo, Nezahualcóyotl, lo pregunto: \\ ¿Acaso de veras se vive con raíz en la tierra? \\ No para siempre en la Tierra: \\ sólo un poco aquí. \\ Aunque sea de jade se quiebra, \\ aunque sea de oro se rompe, \\ aunque sea plumaje de quetzal se desgarra. \\ No para siempre en la Tierra: \\ sólo un poco aquí... \\ Cantares mexicanos
}

\section{No para siempre en la Tierra: sólo un poco aquí}

Miguel León-Portilla fue un ilustre pensador, historiador y humanista mexicano, profundo conocedor de las culturas prehispánicas y defensor de la palabra y los derechos de los pueblos indígenas. Los aportes de este intelectual y maestro de maestros a la traducción, recuperación y estudio de la lengua, la literatura y el pensamiento náhuatl son invaluables, dado que propició, a través de investigaciones rigurosas, el redescubrimiento de todo un mundo cuyo estudio en profundidad permanecía postergado, al tiempo que abrió un espacio en la academia y en la sociedad para el reconocimiento y la reflexión en torno de todos estos temas.

A través de su admirable trabajo de recuperación, traducción, interpretación y difusión de la palabra de los antiguos nahuas a partir de fuentes escritas y de tradición oral, León-Portilla se convirtió en uno de los primeros estudiosos latinoamericanos en dar un rostro y una voz a quienes no habían sido aún reconocidos ni escuchados por los representantes de la historia oficial: se trata así de un auténtico precursor. De allí el enorme valor de su recuperación de esta visión de los vencidos, así como de la herencia cultural prehispánica y la tradición indígena: un legado que se debía indagar como el reverso de la conquista, para a su vez contribuir a afirmar la dignidad de las distintas culturas y estudiar en toda su complejidad la historia de México.

Enormemente significativo resulta entonces que el año de su muerte coincida con varios aniversarios: los cinco siglos de la llegada de Hernán Cortés a suelo mexicano (1519); 
la aparición de la primera edición de la Visión de los vencidos (1959), obra decisiva que inauguró nuevos caminos para la comprensión del mundo americano, y los también sesenta años de la publicación del primer número de la revista Estudios de Cultura Náhuatl (1959), editada por iniciativa del Seminario de Cultura Náhuatl que él mismo fundó, junto con Ángel María Garibay, en la Universidad Nacional Autónoma de México. Estos datos permiten valorar aún más el giro fundamental que su obra imprimió a los estudios históricos y antropológicos. De allí que, a pesar de su partida, la palabra de este tlamatini seguirá ocupando un lugar central en la vida de México y de Hispanoamérica.

\section{Un espacio académico para el estudio de la cultura y el pensamiento náhuatl}

Miguel León-Portilla se formó con dos grandes maestros: el arqueólogo Manuel Gamio y el filólogo e historiador Ángel María Garibay. Ya desde que cursaba estudios de maestría en Estados Unidos comenzó a colaborar, por invitación del primero de ellos, en la elaboración de notas y reseñas sobre las antiguas culturas mexicanas. A su regreso al país se dedicó de lleno al estudio de la lengua y la cultura náhuatl bajo la tutela de este último.

Un primer momento clave en su trayectoria es el que marca su decisión de orientarse de lleno al estudio de la lengua, la cultura y el pensamiento en el mundo náhuatl y emprender un acucioso trabajo de lectura e interpretación de los textos. Es así como ingresó a la Facultad de Filosofía y Letras de la UNAM, donde obtuvo su doctorado en 1956 con una tesis dedicada a La filosofía náhuatl estudiada en sus fuentes. En esta obra precursora sustenta la existencia en el mundo náhuatl de un pensamiento filosófico altamente elaborado, cuyas características indaga a través de la lectura e interpretación de documentos hasta ese momento poco estudiados y poco difundidos y a los que dota de nuevo sentido. Publicada ese mismo año, esta obra supera ya las diez ediciones. Traducida además a distintas lenguas, tales como inglés, francés, alemán, ruso y checo, abrió un espacio de diálogo con otras culturas.

También en 1956 León-Portilla fundó, junto con el padre Ángel María Garibay, el Seminario de Cultura Náhuatl, dentro del Instituto de Investigaciones Históricas de la UNAM. Se inauguraba con ello un ámbito de alta jerarquía intelectual para consolidar una nueva línea de investigación. Este seminario está en el origen de la revista Estudios de Cultura Náhuatl, publicación cuyo primer volumen vio la luz en 1959 y continúa apareciendo de manera ininterrumpida hasta hoy.

\section{Visión de los vencidos}

Otro momento fundamental en su trayectoria es la publicación de Visión de los vencidos. Relaciones indígenas de la Conquista (1959). El doctor León-Portilla tuvo a su cargo la introducción, selección y elaboración de las notas para dicha obra, mientras que el padre Garibay llevó a cabo la versión al español de los textos escritos en náhuatl. En el año 2007 apareció una nueva edición, corregida y aumentada, a la que el propio León-Portilla incorporó dos nuevos capítulos. Esta obra resultó originalísima e innovadora para su momento, en cuanto decidió de manera pionera dar voz a una cultura que había sido silenciada y marginada. Este libro, conocido en el mundo entero y traducido a más de veinte idiomas, nos muestra la conquista de México desde la mirada y la experiencia indígena. El efecto multiplicador de su mensaje permitió abrir un espacio social y un ámbito del imaginario compartido donde resonaron las palabras hasta entonces acalladas y se hizo visible un mundo hasta entonces poco conocido. El trabajo de investigación fue un modelo en su campo en cuanto se basó en 
el estudio y versión al español de fuentes originales como los Cantares mexicanos y el Códice Florentino. En este libro desfilan tanto estampas que representan los momentos traumáticos de la conquista como los cantos de tristeza y las elegías que fueron respuesta a la caída del mundo indígena.

Tengo en mis manos la edición conmemorativa que se publicó en julio de 2019, a sesenta años de la primera edición: Visión de los vencidos. Relaciones indígenas de la Conquista, introducción, selección y notas de Miguel León-Portilla, versión de textos nahuas: Ángel María Garibay K. y Miguel León-Portilla, ilustraciones de los códices: Alberto Beltrán, México, UNAM, 2019. Este mismo ejemplar aporta datos elocuentes sobre las numerosas ediciones que tuvo la obra. Se trata, por decirlo así, de un verdadero best seller de la UNAM, obra prominente dentro del conjunto del fondo editorial universitario que ha alcanzado además la más amplia circulación dentro y fuera de México. Publicada por primera vez en 1959 bajo el sello editorial de la UNAM, con una extraordinaria difusión que llega a varios cientos de miles de ejemplares, es también una de las obras más consultadas dentro de la colección conocida como Biblioteca del Estudiante Universitario. La historia del libro ameritaría un capítulo aparte: dentro de dicha colección de la UNAM aparecieron veintinueve ediciones entre 1959 y 2007 , año este último en que se publicó la nueva edición corregida y aumentada, que ya alcanza a su vez trece reimpresiones. Se cuenta también con varias ediciones especiales y conmemorativas (particularmente las de 1974 y 2019), además de las publicadas en otros países y las numerosas traducciones de esta obra a más de veinte lenguas.

Nos encontramos ante una lectura necesaria, que incorpora a la concepción tradicional de la historia mexicana esta visión de los vencidos, y con ello enriquece desde una nueva perspectiva las anteriores versiones de la historia oficial. Convertida hoy en libro de texto obligatorio para muchos niveles escolares, es también una obra clave para una concepción más completa de la nacionalidad mexicana, y es a su vez una carta de presentación de México para el mundo. Cito las palabras que escribe en la contraportada José Emilio Pacheco:

Hasta 1959, cuando apareció por primera vez este libro, ya tantas veces reeditado, el único testimonio difundido sobre la Conquista era la crónica victoriosa de los propios españoles. Miguel León-Portilla tuvo el incomparable acierto de organizar textos traducidos del náhuatl por Ángel María Garibay para darnos la Visión de los vencidos: la imagen que los indios de Tenochtitlan, Tlatelolco, Tezcoco, Chalco y Tlaxcala se formaron acerca de la lucha contra los conquistadores y la ruina final del mundo azteca.

Relatos de los presagios que anunciaron el desastre, descripción del avance de Cortés, crónica de la batalla heroica de los antiguos mexicanos en defensa de su cultura y de su misma vida, elegía de una civilización que se perdió para siempre, gran poema épico de los orígenes de nuestra nacionalidad, Visión de los vencidos es ya un libro clásico y una obra de lectura indispensable para todos los mexicanos.

Resulta también interesante pensar la Visión de los vencidos como una obra que transformó el estudio de la historia de México al incorporar la versión indígena de los hechos que sucedieron a la llegada de Cortés, de modo que se convirtió en adelantada respecto de toda una línea de estudios dedicados a la recuperación de las lenguas y culturas americanas prehispánicas que fueron marginadas y silenciadas durante las etapas de conquista y colonización. Algunos autores han planteado la posibilidad de poner esta obra en relación con la constelación de los enfoques latinoamericanos contemporáneos ligados a los estudios subalternos o postcoloniales. Desde luego que se debe ser muy cauteloso a la hora de intentar establecer sin más un puente entre estas distintas formas de acercamiento para no incurrir en simplificaciones, pero no 
cabe duda de que al introducir el estudio de la cultura náhuatl y respetar su dignidad, al reconocer que se le debe dedicar un espacio académico y un estudio en profundidad conforme a los requisitos lingüísticos y antropológicos más estrictos, se otorga visibilidad, jerarquía y presencia a un pasado-presente por mucho tiempo obliterado.

Pensemos que con Visión de los vencidos León-Portilla contribuye a abrir el espacio a una amplia red de estudios que no ha cesado de aumentar desde entonces. La mirada singular de León-Portilla y su largo camino de rescate de las culturas del centro de México, así como su profundización en el conocimiento de la lengua, la literatura, la cultura y el pensamiento náhuatl, en un interés que lo acompañó hasta los últimos años de su vida, muestran que nunca decayó su amor por "las antigüedades mexicanas".

Como lo ha mostrado Noé Jitrik, América Latina ha sido precursora en los estudios de la cultura, en una línea de investigación amplia, relacional y crítica que comenzó mucho antes de los que hoy se conocen como estudios culturales. En efecto, la preocupación por la indagación de los fenómenos culturales y la interpretación de los textos en su relación con la historia y la cultura tiene larga data en nuestra región, y muchos estudiosos han sido adelantados respecto de lo hecho en otras partes del mundo. Otro tanto podemos decir sobre la obra de León-Portilla, quien plantea un nuevo punto de vista y marca un hito en el estudio de nuestra tradición cultural, en cuanto reconoce la especificidad y dota de la más alta dignidad al estudio de la herencia indígena, en una contribución de enormes repercusiones que representará un cambio de eje en los estudios históricos y culturales de nuestra región, hará época y dejará una huella imborrable.

\section{La palabra en el mundo náhuatl}

La recuperación que hizo León-Portilla de la antigua palabra y de la obra de poetas del mundo náhuatl, Nezahualcóyotl entre ellos, a partir de un profundo estudio y una rigurosa versión al español de fuentes indígenas hasta ese momento prácticamente desconocidas, le permitió sentar las bases para indagar las claves de toda una visión de mundo así como avanzar en el conocimiento de una literatura, una ética y una estética cuyos alcances se hacen más comprensibles a partir de su puesta en diálogo con aquel complejo entramado de "metáfora y símbolo" que el estudioso identificó como "Flor y canto". Así lo anuncia ya en otra de sus obras pioneras, Trece poetas del mundo azteca (1978), donde recupera la presencia de "los poetas del mundo náhuatl" en cuanto "verdaderos maestros de la palabra, acreedores al título de tlamatini, "el que sabe algo', el que medita y discurre sobre los antiguos enigmas del hombre en la tierra, el más allá y la divinidad". En una prosa que reúne, como los textos que él mismo estudia, arte y sabiduría, León-Portilla nos abre a otra de las grandes líneas de investigación en torno a la palabra que nunca abandonará y continuará explorando a través de sus trabajos posteriores, como lo muestra la valiosa iniciativa de recuperación integral de los Cantares mexicanos.

\section{Fray Bernardino de Sahagún}

Otro de los grandes aportes de León-Portilla es el estudio exhaustivo y la recuperación de la obra de Fray Bernardino de Sahagún. Él nos recordó más de una vez que el admirable trabajo del fraile franciscano constituye un aporte, una clave, para la comprensión del mundo náhuatl, así como también un precedente invaluable en la búsqueda de métodos de investigación antropológica. La obra de Sahagún, adelantado de la investigación etnográfica, ingresó en octubre de 2015 
a la lista de las obras que la UNESCO considera parte fundamental de la memoria del mundo, en cuanto pertenecen al legado de la cultura universal. Entre los numerosos textos y conferencias que León-Portilla dedicó a este precursor del conocimiento de las antigüedades mexicanas se cuentan Bernardino de Sahagún, pionero de la antropología (1999).

\section{Encuentro de dos mundos}

En 1985 me tocó editar en la revista Cuadernos Americanos una interesante polémica entre León-Portilla y Edmundo O'Gorman en torno a la propuesta formulada por el primero de reemplazar la noción "descubrimiento de América" por la de "encuentro de dos mundos". Se acercaba el quinto centenario de la llegada de Colón, y se repensaba el nombre del llamado "descubrimiento". Hoy, al revisar su seguimiento y lectura de la obra de Sahagún y su admiración por el modo en que el fraile franciscano fue al encuentro de la cultura náhuatl y quedó deslumbrado por ella, comprendo mejor los alcances de esta postura de León-Portilla, en contraste con la idea de "invención" de América de O'Gorman. Considero que sería enormemente interesante a su vez reabrir y poner en diálogo hoy ambas lecturas con otras propuestas en la materia, como las de Aníbal Quijano.

\section{Huehuetlatolli}

Una de las derivaciones de los estudios de León-Portilla que alcanzó vida propia es la difusión de los huehuetlatolli o testimonios de la antigua palabra, algunos de los cuales, como es el caso de los "Consejos del padre náhuatl a su hija", retomó en su momento mi propio padre, Gregorio Weinberg, en sus Modelos educativos en el desarrollo histórico de América Latina (1981) para dar ejemplo de los primeros métodos de enseñanza de que se tenga memoria en nuestra América, consistentes en la transmisión de los modelos e ideales de la cultura de los antiguos mexicanos a través de la "plática de los ancianos" que transmitía de generación en generación todo un cuerpo de doctrina y sabiduría. Recuerdo también emocionada que años después el doctor León-Portilla nos hizo llegar un primoroso texto de su autoría titulado "Amerindia en América Latina", que se publicó como parte del libro Del tiempo y de las ideas (2000) preparado en homenaje a mi padre y es muestra de un rico diálogo intelectual.

\section{Obras}

Entre sus principales libros recordemos La filosofía náhuatl estudiada en sus fuentes (1956); Siete ensayos sobre cultura náhuatl (1958); Visión de los vencidos. Relaciones indígenas de la Conquista (1959); Los antiguos mexicanos a través de sus crónicas y cantares (1961); El reverso de la Conquista: relaciones aztecas, mayas e incas (1964); Trece poetas del mundo azteca (1967); Tiempo y realidad en el pensamiento maya (1968); Nezahualcóyotl. Poesía y pensamiento: 1402-1472 (1972); Trece poetas del mundo náhuatl (1978); México-Tenochtitlan, su espacio y tiempos sagrados (1979); Hernán Cortés y la Mar del Sur (1985); Cartografía y crónicas de la antigua California (1989); Literaturas indígenas de México (1992); Quince poetas del mundo náhuatl (1994); Francisco Tenamaztle (1995); La flecha en el blanco. Francisco Tenamaztle y Bartolomé de las Casas en lucha por los derechos de los indígenas 1541-1556 (1995); Bernardino de Sahagún. Pionero de la antropología (1999) y Tonantzin Guadalupe. Pensamiento náhuatl y mensaje cristiano en el "Nican mopohua"(2001). En 2002 publicó, junto con su esposa Ascensión Hernández de León-Portilla, la edición facsimilar, con estudio introductorio, transliteración y notas, del Arte de la Lengua Mexicana de Fray Andrés de Olmos, obra fundamental para el estudio del náhuatl clásico. Dirigió 
además el monumental proyecto de traducción y edición completa del manuscrito de los Cantares mexicanos, obra en que intervino un valioso equipo de investigación y cuyos primeros dos volúmenes fueron publicados en 2011, seguidos de un tercer volumen publicado en formato digital en 2019.

\section{Reconocimientos}

El doctor León-Portilla recibió innumerables reconocimientos a su trabajo, incluida su designación como el primer extranjero en obtener la presea "leyenda viva" que otorga la Biblioteca del Congreso de Washington. Se hizo acreedor de las más altas distinciones que se otorgan por parte de la UNAM, como el Premio Universidad Nacional (1994) y el nombramiento como investigador emérito de esta casa de estudios (1988). Alcanzó las más altas distinciones en su campo, como la Presea Manuel Gamio al mérito indigenista (1983) o la Medalla al mérito Fray Bernardino de Sahagún (2014).

Fue reconocido además con la mayoría de las principales distinciones que otorga México a sus figuras más destacadas: el Premio Nacional de Ciencias Sociales, Historia y Filosofía (1981), la Medalla Belisario Domínguez (1995), el Premio Internacional Alfonso Reyes convocado por la Capilla Alfonsina y la Universidad Autónoma de Nuevo León (2000), el premio Alfonso Reyes entregado por El Colegio de México (2015) o la Medalla Nezahualcóyotl otorgada por la Secretaría de Educación Pública de México (2019). Recibió también numerosos doctorados honoris causa a nivel nacional e internacional, así como la Gran Cruz de la Orden de Alfonso X el Sabio (1999), la Orden de las Palmas Académicas por parte de Francia (2000), el Premio Internacional Menéndez Pelayo (2001) y el Premio Bartolomé de las Casas (2001), entre muchos otros.

Desempeñó altos cargos, como el de representante de México ante la UNESCO. Fue miembro de la Academia Mexicana de la Historia, la Academia Mexicana de la Lengua, El Colegio Nacional, así como director del Instituto Indigenista Interamericano de la Organización de los Estados Americanos.

Supongo que uno de los títulos que más debe haberlo enorgullecido es aquel nombre entrañable con que se lo recuerda en México: tlamatini, hombre sabio.

\section{Una lección para la academia}

Recordemos también que la amplia obra de León-Portilla abarca no sólo trabajos especializados que son hoy referencia obligada para los estudiosos de las culturas prehispánicas del centro de México, sino también libros de lectura necesaria para los alumnos de distintos niveles educativos. Cumplió así este pensador y escritor uno de los grandes anhelos de quienes hacen trabajo intelectual: que sus obras lograran llegar tanto a los investigadores maduros como al gran público, y en especial a los jóvenes, convertidas en lecturas despertadoras de conciencia, difundidas y multiplicadas a través de las escuelas, las bibliotecas y los distintos sectores de la sociedad. Varias de sus obras, ya clásicas, interesan a quienes buscan conocer la historia, la cosmovisión y la literatura de los pueblos indígenas, y constituyen algunos de los títulos publicados por la UNAM que han alcanzado y siguen alcanzando los más numerosos tirajes y el mayor número de ediciones, y de este modo logran una amplia lectura y una notable circulación en su país y en el extranjero. La obra de León-Portilla representa así un modelo de las posibles formas de contribución de los universitarios a su sociedad y un ejemplo del modo en que una institución 
pública como la UNAM logra fortalecer su presencia en la vida cultural a través de los aportes de sus académicos. Otro tanto podemos decir de las innumerables traducciones de su obra a distintos idiomas del mundo: inglés, francés, alemán, italiano, hebreo, polaco, sueco, húngaro, portugués, japonés, chino mandarín, entre otros. Recordemos además que la Visión de los vencidos-como Pedro Páramo, de Juan Rulfo- ha sido traducida también al náhuatl.

Fue asimismo León-Portilla un precursor en la apertura de espacios del conocimiento y fundador de instituciones: entre ellas, el Seminario de Cultura Náhuatl, el primero en su tipo, al que se fueron sumando de manera creciente estudiosos y hablantes de esta lengua. Fue director durante doce años del Instituto de Investigaciones Históricas de la UNAM, y dentro del mismo logró abrir una sección destinada a los estudios prehispánicos, a la que se incorporaron antropólogos, lingüistas, arqueólogos, y que, como observa José Rubén Romero, resultó ser a su vez el "núcleo generador" de otra entidad: el Instituto de Investigaciones Antropológicas de la UNAM. Todo un modelo del proceso por el cual la ampliación de un campo de estudios resulta en la apertura estratégica de nuevos espacios académicos: en el seno de una entidad dedicada a la historia surge una entidad dedicada a la antropología. Y este fenómeno alcanza las dimensiones de un símbolo, en cuanto traduce el reconocimiento del lugar que los aportes de la antropología y la cultura prehispánica deben tener en el estudio de la historia de México y de América toda.

Además de haber sido uno de los grandes adelantados, como maestro indiscutido del náhuatl clásico, del conocimiento de las lenguas indígenas, logró que en la Facultad de Filosofía y Letras de la UNAM y en otros ámbitos se abrieran cursos de lengua, literatura y cultura náhuatl. Mantuvo de manera incansable un activo trabajo como maestro universitario y tutor del programa de posgrado en Historia y Estudios Mesoamericanos de la UNAM, donde formó a jóvenes investigadores y destacados discípulos.

Como se dijo más arriba, León-Portilla fue fundador, junto con Ángel María Garibay, de una revista indispensable para el campo: Estudios de Cultura Náhuatl, editada por él mismo durante muchos años. Participó en los comités editoriales de las revistas Arqueología Mexicana, Tlalocan, California History, Artes de México y del Mundo, así como del comité de Latin American Indian Literatures. Como director del Instituto de Investigaciones Históricas dio impulso a los estudios y publicaciones sobre el México indígena y apoyó innumerables trabajos en la materia hechos por especialistas de la UNAM y de otras entidades nacionales y extranjeras, tal como consta en los diferentes números de la revista Estudios de Cultura Náhuatl.

\section{Tlamatini}

Cierro este homenaje con la invocación del nombre con que se designa al sabio y conocedor de las cosas en la cultura náhuatl, porque así se recordará en efecto a este pensador, escritor y maestro de maestros que fue Miguel León-Portilla. Modelo de inteligencia y optimismo, de trabajo exhaustivo y creatividad, modelo de compromiso y de vínculo entre la academia y la sociedad, la obra de León-Portilla abrió también caminos para un encuentro virtuoso entre el talento y el apoyo que las instituciones y sistemas de investigación consolidados pueden y deben dar al trabajo de nuestros estudiosos e investigadores así como al espacio social que debería por fin asignarse de manera indiscutida (esto es, no sometida a los avatares políticos o económicos) a las distintas disciplinas del conocimiento en los países de América Latina: un círculo virtuoso que permita lograr una relación franca entre los investigadores, la sociedad y las instituciones públicas. 
Una vida ejemplar, una familia ejemplar, un maestro ejemplar, su cordialidad, su sencillez, su capacidad didáctica, su carisma, su sentido del humor, lo convirtieron en un amigo, en un académico, en un colega, en un maestro sabio y querido, en una presencia insustituible en la vida de México y de nuestra América, a quien más de una vez se le escuchó decir que consideraba una maravilla que la universidad le pagara un sueldo por dedicarse a trabajar en aquello que lo apasionaba.

Un círculo virtuoso entre la investigación, la docencia, la extensión académica y la posibilidad de incidir en las políticas públicas, como lo muestra su larga y fructífera labor para propiciar la modificación del marco legal vigente en su momento para lograr el reconocimiento de la dignidad y el derecho al uso de la lengua materna y la posibilidad de una educación plurilingüe e intercultural que, como se lee en el artículo tercero constitucional, deberá estar "basada en el respeto, promoción y preservación del patrimonio histórico y cultural".

En una nota publicada en 2019 en el portal electrónico de la Secretaría de Educación Pública, que recoge las palabras de Javier López Sánchez, miembro del pueblo mayatseltal de Chiapas, y por entonces Director General de Educación Indígena, se mencionan "las aportaciones de Miguel León-Portilla en la defensa de las comunidades indígenas y sus expresiones culturales", al tiempo que se recuerda que "la diversidad de las lenguas indígenas es factor de identidad que nos une al pasado y proyecta hacia el futuro, al ser un vínculo de identidad que contribuye en la vida intelectual y cultural de las comunidades".

\section{En defensa de las humanidades}

La obra de León-Portilla representa también una defensa del valor de las humanidades para la salvación de la esfera de sentido que nos envuelve y el horizonte de futuro que nos dota de perspectivas, así como una postura generosa en favor del modo abierto, dialógico, incluyente y comprometido en que las humanidades pueden trabajar en relación con la sociedad.

Autor de libros fundamentales que incluyeron otra realidad hasta el momento ignorada, defensor de un modelo de investigación histórica, lingüística y cultural nunca reñido con los aspectos éticos y estéticos de la reflexión, León-Portilla fue consecuente con la permanente exigencia de apertura de espacios para las lenguas y las literaturas indígenas, desde su apoyo a la creación de la asociación de Escritores en Lenguas Indígenas (1993) hasta su contribución para lograr la reforma constitucional por la cual hoy se reconoce el derecho de los pueblos indígenas a usar las respectivas lenguas maternas y se acepta que su cultura es parte del legado de la nación mexicana.

Para terminar, afirmo que nos legó también para siempre esta poesía, dedicada a la memoria de Carlos Montemayor, y que el propio autor tradujo del español al náhuatl, donde nos muestra que cuando muere una lengua muere un mundo: 
Cuando muere una lengua

las cosas divinas,

estrellas, sol y luna;

las cosas humanas,

pensar y sentir,

no se reflejan ya

en ese espejo.

Cuando muere una lengua todo lo que hay en el mundo, mares y ríos,

animales y plantas, ni se piensan, ni pronuncian con atisbos y sonidos que no existen ya.

Cuando muere una lengua entonces se cierra a todos los pueblos del mundo una ventana, una puerta, un asomarse de modo distinto a cuanto es ser y vida en la tierra.

Cuando muere una lengua, sus palabras de amor, entonación de dolor y querencia, tal vez viejos cantos, relatos, discursos, plegarias, nadie, cual fueron, alcanzará a repetir.

Cuando muere una lengua, ya muchas han muerto y muchas pueden morir. Espejos para siempre quebrados, sombra de voces para siempre acalladas: la humanidad se empobrece.
Ihcuac tlahtolli ye miqui, mochi in teoyotl, cicitlaltin, tonatiuh ihuan metztli; mochi in tlacayotl, neyolnonotzaliztli ihuan huelicamatiliztli, ayocmo neci inon tezcapan.

Ihcuac tlahtolli ye miqui, mochi tlamantli in cemanahuac, teoatl, atoyatl,

yolcame, cuauhtin ihuan xihuitl ayocmo nemililoh, ayocmo tenehualoh, tlachializtica ihuan caquiliztica ayocmo nemih.

Inhuac tlahtolli ye miqui, cemihcac motzacuah nohuian altepepan in tlanexillotl, in quixohuayan. In ye tlamahuizolo occetica in mochi mani ihuan yoli in tlalticpac.

Ihcuac tlahtolli ye miqui, itlazohticatlahtol, imehualizeltemiliztli ihuan tetlazotlaliztli, ahzo huehueh cuicatl, ahnozo tlahtolli, tlatlauhtiliztli, amaca, in yuh ocatcah, hueliz occepa quintenquixtiz.

Ihcuac tlahtolli ye miqui, occequintin ye omiqueh ihuan miec huel miquizqueh. Tezcatl maniz puztecqui, netzatzililiztli icehuallo cemihcac necahualoh: totlacayo motolinia. 


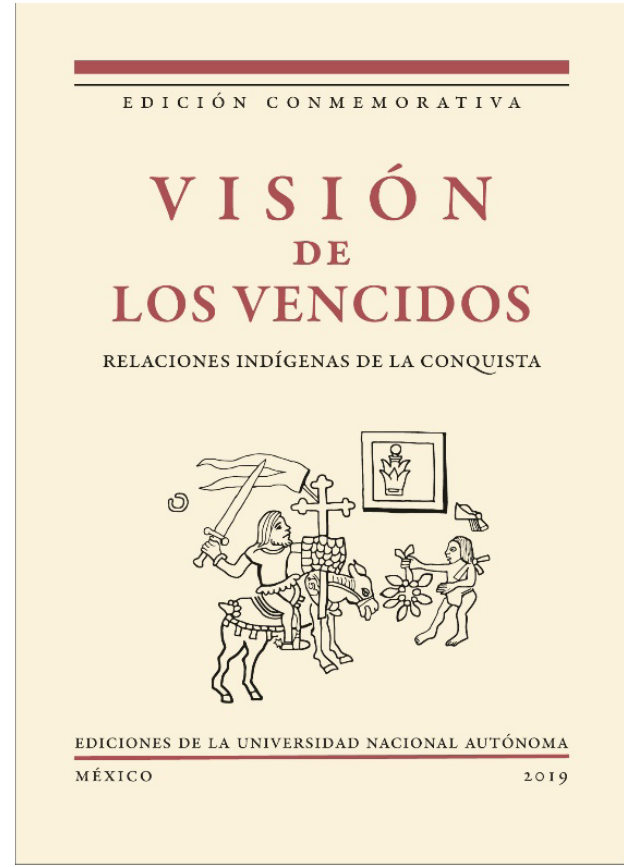

Edición conmemorativa de Visión de los vencidos (1959), México, UNAM, 2019. 